\title{
The analysis of development strategies of logistics information platform in mobile Internet era
}

\author{
Du Juan , Zhao Renren \\ School of Economics and Management \\ Changchun University of Technology \\ Changchun, China \\ dj737@sohu.com; 1051639630@qq.com
}

Key words: logistics information model, logistics platform, the problem, strategy

\begin{abstract}
As the demand of manufacturing and trading enterprise of low cost and high guilty logistics service to logistics industry, the logistics information model in former mobile Internet era have been can't meet the requirements of the logistics industry. So, under the requirement the policy and industry, many enterprises make the full use of internet to develop logistics platform, reduce logistics cost and speed up the service response. In this article, through analyzing the problems that the logistics platform face in mobile Internet era, analysis the gain and loss and put forward the development strategy and provide a reference for the future development.
\end{abstract}

\section{Logistics information models before mobile internet era}

The former mobile Internet era is relative to the mobile Internet era .During this period, the combination of mobile communication and Internet is not yet ripe. Human activities is limited to the Internet communication and individual treatment of the era, and even cell phones or is it just a simple communication function, query information have to use the computer.

The main mode of logistics information and their characteristics before mobile Internet era

Before the Internet is not fully used in the logistics information industry, the communication about the logistics information among the industry is usually off the line . The main way is joining the truck owners and shippers by the distribution stations. In order to issue the information of freight source more convenient, the distribution network turns up with the help of the Internet .But when the driver uses the Internet inconveniently outsides all years ,the QQ group has become a auxiliary way to find freight source.

The distribution stations who usually provide service to middle and small-sized enterprises grasp the information of truck source and freight source in a certain region. They make a living by charging the information or the price difference as intermediary agents . The main function of distribution station is looking for return cargo for individual truck or some transportation company to promote the exchange of information and to facilitate transactions between transportation enterprises and owners of cargo. But the simple mode of the distribution stations makes that the market competition lacks of sequence, the link is longer and the industry price is chaotic. Restricted to region, the distribution stations can only serve the local transport demand, or even just serve the certain line between this locality and somewhere. So it is difficult to form stable relationships of cooperation with individual trucks or transportation enterprises.

Distribution network is implemented by Internet, and it has broken through the region. Generally they are built by local distribution stations in the service of the whole city and some distribution network can cover all over China. The distribution network really can promote the information exchange, but the form of releasing network information like the trucks who is always in outside. 
So the distribution network just makes it easy to release information for distribution stations. But the information becomes no value when nobody looking for it.

Relative to the distribution network, the QQ group is more convenient to find useful information. The trucks will call up the local distribution stations they are familiar firstly when they have arrived or on the way to someplace. If they don't get the appropriate freight source, they will look through the information by QQ groups, or provide their own messages to the QQ groups. QQ group is useful for both the trucks and the freight, but usually the two sides have no cooperation before, and believing apposite side is risky. Similar to QQ group, the WeChat group has the same model, which will be the main mode of demanding information before the logistics platform developed in the new era.

The advantage of logistics information models the above-mentioned

No matter the distribution network or the QQ groups, that the distribution stations control the most of the supply of goods. Distribution station holds the majority of the supply of goods of small and medium-sized manufacturing enterprises and also is the main way to looking for return cargo of the individual truck or the transportation company. During this period, logistics information model has the following questions: i ) some distribution states raise the carriage to the shippers, and demand of the trucks a low carriage by their own advantages, then they will get the price difference, which makes carriage of the whole industry chaotic. The cost that the distribution stations charge every year is about 80 billion, which is about $7 \%$ of the total logistics cost; ii ) the distribution stations always want to find the lowest carriage from the trucks when they receive the task the consignor, which limits the response speed to the customers; iii)charging the trucks or charging the shippers makes a long transaction link. Don't make sure about the return goods or the carriage is too low so that the trucks choose empty driving or overload, which waster the resources and increases the potential safety hazard. Idle transport capacity and transport capacity shortage are both existent that is the biggest problem the transportation face in the period.

Before the mobile Internet era, the slow communication exchange makes a slow speed of development. The industry is badly in need of a new logistics information mode which can solve the problem of allocation of cargo, manage the trucks and dispatch the trucks. In recent years, there have been several logistics platforms to solve these problems in China.

\section{The characteristics of the logistics platforms in mobile Internet era}

The problems the platform trying to solve in this era

The problems of the logistics information service industry

The cost is too high, the information is inaccurate and not in time, and the platforms can not meet the fluctuant demand and are unable to integrate service as supply chain, so many problems, like quality of service, constitute the key problems the logistics industry faces. The following questions are existing in the industry: $\mathrm{i}$ ) the mismatching between the trucks and the goods, the not timely release of information and update of information; ii )too hard to realize the real-time system of truck; iii)the lack of effective supervision to the flow of goods and transportation schedule of goods; iv)lack of E-Commerce system. ${ }^{[1]}$

The problems the platform trying to solve

An effective logistics platform must have three basic functions, the vehicle monitoring, scheduling management and logistics trading to improve logistics information communication and improve the efficiency of communication so that the relevant subjects can control the real- time state of the truck and the implementation of the invoice, improve the management level and make the supply and requisitioning parties of the logistics services get enough trading information on the platform to realize the ideal trade. So the platforms are trying to solving the problems: i ) increasing the vehicle and invoice information on the platform greatly to improve the efficiency of matching; ii guaranteeing accurate information on the platform ,guaranteeing the quality, control risk and monitor the real-time state of the truck; iii) making the trucks and the goods trade on line and attracting more platform parties to use he platform as a result that the users can realize 
self-propagation; iv)perfecting the system and striving for the main business.

The business model of the logistics platform

Compared with the logistics information model in former era, a prominent feature of logistics platform is the emergence of mobile client, which makes it convenient for the trucks to query information or locate a truck by mobile phone. In the early stage, when the platform is integrating trucks and the manifests, they profit by charging the information acted as a distribution state. They have no obvious advantages relative to the distribution states. On the contrary, to a certain extent, the distribution stations hinder the growth of the amount of information on the platform. So platforms will add some services around the vehicle on the platform for example, gas filling card, the risk of damage, etc. On the one hand, this way can increase their income. On the other hand, it can attract more trucks to their own platform. When information increase to a certain number, the platform will provide some value-added services as a profitable product, such as payment of freight, finance release even the rental information of warehouse.

\section{The analysis of four domestic logistics platforms}

As realizing the industry more and more deeply, there are many domestic enterprises having begun to have operated their own logistics platform. Here, I will analyze five companies about their goals and whether they achieve their goals, in order of the time they were launched, then give a simple evaluation.

"YunManMan"

"YunManMan" belongs to the subtle information consulting co., LTD., Shanghai, launched in November 2013 and the founder is Zhang Hui. In November 2014 "YunManMan" announced that they have got $\$ 5$ million investment from the speed of light An Zhen China Venture capital fund for round A funding in March. The news said that the round $\mathrm{C}$ funding also has been determined. ${ }^{[2]}$

The objects of service of "YunManMan" cover all types of cargo and vehicles. Their goals are to satisfy the transportation companies, the distribution stations and small and medium-sized enterprises the requirement about the vehicles for long-distance and truck-load transportation. At the same time, they improve the efficiency of matching the vehicles and the cargo, reduce the rate of empty return, improve the efficiency of the owner of the cargo to find an appropriate vehicle and improve the efficiency of the logistics industry.

"YunManMan" has two clients, "YunManMan driver" and "YunManMan shipper". The information will be pushed to the users and the main task is matching the vehicle and the goods. But the vehicle can not order the manifest and only can find the manifest be released in the same day. The vehicle owner and the consigner still communicate with each other off the line. The platform just provides the information and has nothing practical significance to online transactions and monitoring the vehicle is still by the way of monitoring the phone. So "YunManMan" stays on stage of increasing the amount of information. In addition to continuing to increase the amount of information, they also need to exploit the function of online transactions, steady the current users and attract more customers at the same time if they want to develop the platform

"Luo Ji"

"Luo Ji" logistics is attracted to Beijing branch network technology co., LTD., was established in Beijing in June, 2014, and was found by Song Rui. "Luo Ji" has got the round B investment in March, 2015. ${ }^{[3]}$

"Luo Ji" wants to solve the problem of the match between the trucks and the cargo. But they have their own requirement: centralized logistics data management, intelligent distribution, data synchronism in logistics center, receipt synchronism, ordering truck line, information synchronism between logistics companies, returning the goals to avoid empty.

"Luo Ji" has two kinds of software for the trucks and consignors on the main line, "Luo Ji looking for vehicle" and "Luo Ji looking for cargo". And they have been able to achieve its stabled goals, but the process is not out of line. The trucks and the consignors still need to make a call, and only they reach an agreement, can they go to deal, which will inevitably result in that the two sides finish the whole process directly without any operation online. Now "Luo Ji" has made revise that 
the vehicle users can choose to accept the manifest pushed by the system or not according to their own situation. But there is still not the function of making an appointment with the cargo. And "Luo Ji" monitors the phone to monitor the truck.

"CheWang"

On September 16, 2014, Beijing zhongjiaoxingroad Internet of vehicle co., LTD. officially launched the integrated Internet of vehicle services platform for the national vehicle---"CheWang". The general manage is Zhang Tong.

The target of "CheWang" is the service of Internet of vehicle, including refueling service, insurance, maintenance rescue service, finance, credit reporting systems, etc. So the platform serves all the logistics company, drivers, shippers and other industries. They hope that all the services about the Internet of vehicle can be integrated on the platform.

"Che Wang" can order the manifest by "grabbing". Then it will generate a waybill in shipper client. The process is not out of line, and the process of transaction can not be seen on line. If the shipper wants to know the flow of the cargo, they have to monitor the truck or the phone. "CheWang" develops the Internet of vehicle service based on the amount of trucks on platform, but the truck makes a living by manifest. If the driver has no living, the service has no value.

"HaoDuoChe"

"HaoDuoChe" is the product of Shenzhen yiliu technology co., LTD. The chairman is Zhang Jingtao and the executive general manager is Yang Yelong. On October 15, 2014 at the scene of the eighth summit about the transparent management to the transport process, "HaoDuoChe" platform was released.

"HaoDuoChe" is a service platform about vehicle information. They want to create massive and real vehicle resource pool. They provide free service like management of the familiar trucks, looking for vehicle, and transparent management of the waybill to the logistics enterprises. They provide free services like sharing the truck state, acquiring business, to join a motorcade and the accumulation of credit service to the individual truck. As a result, the companies can find and use a truck more conveniently and the drivers can gain and transport cargo more easily. ${ }^{[5]}$

"HaoDuoChe" can order the manifest and catch the manifest pushed at any time. They can compensate for the false information or the problem of empty due to users. There is no online transaction. And the way of location is not limited to the satellite, but there are some functions being limited if the users don't hold the yiliu GPS.

"HaoDuoChe" has its own advantage that long-term cooperation logistics companies can keep the amount of information. But it can not show the value of platform in the Internet era without realizing the online trading. Take advantage of the current preponderance and exploit function of online trading which will attract more users, the "HaoDuoChe" will develop rapidly.

\section{The problems existing in the domestic logistics platforms}

At present, many trucks and shippers have know the logistics information platforms and the problems they try to solve, and a part of main babies have begun to use the problem, which is useful to the following generalization of the platform. But the problem is not solved completely in a long time, which affects adhesiveness of users negatively. At a result, the amount of information can't be kept. Domestic logistics platforms still need to solve the following problem.

Insufficient information on platform

Solving the matching between trucks and cargo requires a mass of information on the platform, including the trucks and the goods. The greater the amount of information makes the higher matching degree and the shorter time it needed. This problem is still not solved.

Inaccuracy of the information on platform

Now the most of the vehicle information comes from mobile phone location and the invoice information was released by staff. The shipper may issue the information on a better platform actively, but update it positively. So the most of vehicle information just is a truck position not its exactly "state". So pushing information is just according to the truck's location. The platform has 
not considered the complexity of logistics industry when it was been building, including many details such as vehicle statues, empty or full, having got the manifest or not. In addition, the mobile phone positioning is to identify the driver and the owner, which makes a mistake when looking for a truck. The invoice information also has a similar problem. If you can't make sure the accuracy of the invoice when released, it will be impossible when updated.

Offline deals are still dominant

The both sides choose to trade online only when they trust each other completely or they think all risks can be solved. People have been used to the offline transaction for a long time, and they all have their own comfort zone. It will be a challenge to break the traditional model for the trucks and the shipper or the platform.

Deviate from the main business

The distribution stations contact their familiar trucks firstly when they get their assignments, and the trucks contact their familiar distribution stations firstly when they need manifests. Only when the both sides can't reach an agreement, will they choose other ways, which leads to that morn than half of the logistics information is not through the logistics platform. The cause of the situation is that the both sides have used to the traditional model. The one who can move the information to his own platform will be the main platform.

The current clients are built for individual trucks, not for the big enterprises. But the clients can not solve the problem of team management, waybill management, the sharing of the capacity and the like.

\section{The development strategies of logistics platform}

Increase the amount of information on the platform

The most important thing is the match between trucks and goods in the whole process of the development of platform. The basis is having a large amount of information. But integrating the trucks and the goods at the same time may cost lots of human, physical and financial resources, so we should begin with he passive side - the vehicle. In the past process of distribution, a truck should pay the distribution stations about 20 or 30 thousands for the manifests every year, and pay 2 or 3 days in average for one manifest. Most of the small and medium-sized enterprises choose to hand their goods to the distribution states, but not to only one distribution station. The distribution station also holds some other available information. So it has a small effect on the station to loss one invoice. Therefore, the platform has more attraction to the trucks. So when we integrate the information, we should be centered on integration of vehicle information, and attract manufacturing and trade enterprise to issue invoice by the vehicle information when it reaches to a certain number. Provided that the truck should update its state in time, or strictly, it should install the position equipment.

Guarantee the accuracy of the information

Change the original model of position by mobile phone, and display information on the platform, in addition to the location of the vehicle, other states are needed, including empty or not, loading or not, ordering or not. Another problem is the visualization of the waybill. The current model is that the owner of the goods makes a call to the driver to confirm the location of the truck after it loaded. The desired model is that the location of the truck and the flow of the goods are all displayed on the platform, including the waybill generated in the end and the receipt. This requires that a platform has relevant "button" when it was built to complete the online communication of the whole transaction.

To online trading

To want to complete the whole online trading process, it may need to cut off the possibility of communication offline. The two sides can get the contact information only after they have finished the ordering process. The truck can't order receiving, and the invoice can't accept other trucks' requirements before the two sides cancel the indent. It is breaking the traditional for the platform and it's a challenge for both sides. The two sides are likely to be the first cooperation, so the platform should ensure the reliability of the information when they integrate it. 
Increas the logistics scheduling system

Idle capacity and capacity shortage are concomitant is one of the biggest problems of platform in this period, and the clients can't solve this problem completely. So add a complete scheduling system on the platform for logistics enterprise that they only need a simple click can manage the entire logistics operation and realize sharing resource.

In China refrigeration network example, introduce the methods to solve the relating problems. China refrigeration network is a platform built specially for refrigeration business. It uses the way that the truck driver reports the states to make sure the truck can be used, and at the same time, they can order the invoice. For the refrigeration business companies, China refrigeration network provides the refrigeration business system. The users can manage the vehicle, the invoice and the waybill. They can use the platform freely to search the vehicle and invoice information.

\section{References}

[1] Ren Xiaodan. "The demonstration system of logistics professional information services based on Beidou system" [R]. The ninth building digital technology square on the second floor, shangdi north street, Haidian district of Beijing. 2007

[2] Li Guixin "YunManMan":a logistics platform special for truck drivers[R].2014

[3] Song Rui.B2B makes traditional industry more efficient[R].2015

[4] Beijing logistics public information platform. "CheWang"changes your life of the freight[R].Beijing.2014

[5] Xi Congbin. "building the platform of capacity information service," HaoDuoChe" is on the road"'[J], < Logistics technology and application >. phase 11, 2014. 